UDC 340.13:004.9

LBC 67.022.1c51

\title{
THE ROLE OF ELECTRONIC COMPUTER SYSTEMS \\ IN THE IMPLEMENTATION OF THE PRINCIPLES OF LEGAL ACTS SYSTEMATIZATION IN THE RUSSIAN FEDERATION
}

\author{
Oleg A. Mineev \\ Volzhsky Humanitarian Institute, Volzhsky, Russian Federation \\ Gennadiy G. Egorov \\ Volzhsky Humanitarian Institute, Volzhsky, Russian Federation
}

\begin{abstract}
Introduction. The incompleteness of the processes on improving the existing legal norms in their constant dynamic development in Russia forms a continuous urgent problem of legal and technical nature. The aim of this article is the allocation of the role of modern legal reference computer systems in the implementation of the principles of systematization of the existing Russian legislation. Methods. The complexity of this problem involves the use of both legal and "machine-logical" instruments which are required by experts to resolve the problem. Results. The shortcomings of the regulative sphere are marked in the article on the basis of current recording and electronic data, allowing to prove the importance of electronic systems in improving the country's law enforcement practices and offering a number of legal forms to remove them. Conclusions. The authors worked out the following recommendations on improving the existing legislation, in particular: 1) the creation of state-supported data bank of regulatory legal acts of the country and the region; 2 ) the introduction of common forms of improving the practice of codification on the level of subjectivity of the law within state; 3 ) the definition of legal status of the most "popular" legal reference computer systems of the country on the federal level.

Key words: principles of legislation systematization, forms of normative-legal acts perfection, problems of legal norms systematization, gaps of law, electronic systematization of law, electronic recordings of the acting legislation.
\end{abstract}

УДК 340.13:004.9

ББК $67.022 .1 \mathrm{c} 51$

\section{РОЛЬ ЭВМ-СИСТЕМ В РЕАЛИЗАЦИИ \\ ПРИНЦИПОВ СИСТЕМАТИЗАЦИИ НОРМАТИВНЫХ ПРАВОВЫХ АКТОВ В РОССИЙСКОЙ ФЕДЕРАЦИИ}

\author{
Олег Александрович Минеев \\ Волжский гуманитарный институт, г. Волжский, Российская Федерация \\ Геннадий Геннадьевич Егоров \\ Волжский гуманитарный институт, г. Волжский, Российская Федерация
}

\footnotetext{
Введение: незавершенность в стране процессов по совершенствованию действующих норм права при их постоянном динамическом развитии формирует постоянную актуальную проблему юридико-технического характера. Целью данной статьи стало выделение роли современных справочных правовых компьютерных систем в реализации принципов систематизации действующего российского законодательства. Методы: комплексность выделенной проблемы предполагает использование как юридического, так и «машинно-логического» инстру-
} 
ментария, необходимого специалистам при их разрешении. Результаты: отмеченные в статье недостатки развития нормотворческой сферы, основываясь на приведенных актуальных данных учетно-электронного характера, позволили обосновать значимость электронных систем в совершенствовании используемых норм права при реализации правоприменительной практики страны и предложить ряд форм по их устранению. Выводы: в результате проведенного исследования формируются следующие рекомендации по совершенствованию действующего законодательства, в частности: 1) создание государственно поддерживаемого информационного банка данных о нормативных правовых актах страны и региона; 2) введение единообразных в рамках государства форм совершенствования практики кодификации на субъектном уровне норм права; 3) определение на федеральном уровне юридического статуса наиболее популярных справочно-правовых компьютерных систем страны.

Ключевые слова: принципы систематизации законодательства, формы совершенствования нормативных правовых актов, проблемы систематизации норм права, пробелы права, компьютерная систематизация права, электронные учеты действующего законодательства.

\section{Введение}

Актуальность темы публикации связана с наличием в российском законодательстве неопределенности при реализации принципов систематизации действующих в стране норм. Данное положение связано с формированием принципиально новых институтов, которые основаны на условиях современной рыночной экономики, а также показателях правового государства. Следует иметь в виду, что принимаемые нормы права на федеральном, региональном и местном уровнях нуждаются в систематизации.

Принятый в 1993 г. российский новый основной закон стал предпосылкой по становлению новых принципов права, являющихся базовыми технико-юридическими критериями построения как отдельных нормативных правовых актов, так и всего российского законодательства $[10$, с. 106]. Реализация данных принципов направлена на осуществление эффективного функционирования данной системы. Новые условия развития теории права требуют роста значения также и самих принципов по систематизации нормативных актов. Под ними следует понимать основополагающие условия нормативноправового вида, которыми следует руководствоваться как при выборе признаков, так и свойств, а также обобщенных характеристик объективного характера в качестве критериев классификациии построения классификационных схем [8].

\section{Особенности формирования принципов систематизации норм права в РФ}

Различные периоды развития любых государств предполагают формирование потребности в систематизации законодательства [9].
На современном этапе развития государства наблюдается усиление активности на различных уровнях законодательной деятельности органов власти. По данным системы правовой поддержки «КонсультантПлюс», на начало октября 2016 г. в России действует порядка 6239 федеральных норм, и лишь по Волгоградской области их 2 112. Следует иметь в виду, что процессы интеграции российского законодательства с международными правовыми нормами влекут за собой и коллизию в них.

Значимость научно обоснованной и технически обеспеченной систематизации норм права трудно переоценить. При работе с систематизированной правовой информацией законодательные органы намного эффективнее и с меньшей затратой времени смогут выявлять несогласованность, противоречивость, проблемность в правовом регулировании, принимая меры по их устранению.

Теоретический аспект проблемы систематизации норм права взаимосвязан с такими теоретическими категориями, как кодификация, инкорпорация и консолидация норм права. Обобщенная деятельность по упорядочению норм права именуется кодификацией, при этом понятие используется в двух аспектах: узком и широком. В широком смысле кодификация преследует лишь цель технического упорядочения существующих норм права, сведения действующих законов в определенную систему и для более легкого охвата материалов, без внесения при этом изменений в сущность самих законов [2].

Современные справочные правовые компьютерные системы при всей своей востребованности у пользователей четко опре- 
деляют интерес не столько к своду федеральных законов в бумажной форме, сколько к основам законодательства РФ в электронной форме. Это объясняется показателями современного реформирования государственного аппарата в России, подразумевающими четкое выделение совокупности полномочий отдельно для субъектов Федерации и для федерального центра, сокращая предметы совместного ведения.

Затянувшийся переход к рыночным показателям развития экономики, а также интенсификация правотворческих форм деятельности федеральных, региональных органов власти требуют продолжения внедрения компьютерных систем, организации банков разной юридической информации, общефедерального и регионального наполнения справочно-информационных правовых систем, формирования единообразной схемы систематизации права [7]. По нашему мнению, наибольшей эффективностью и перспективностью в плане форм учета, хранения и распространения норм права обладают специализированные компьютерные системы, развивающиеся в России.

Но, к сожалению, государственная поддержка в сфере использования компьютерных инноваций в процессах систематизации норм права на различных уровнях минимальна.

Необходимость решения проблем по упорядочению законодательства сегодня уже вышла за рамки правового регулирования в стране. Ряд авторов [11] уже неоднократно предлагали продолжить работы по созданию модельных форм законодательного характеpa в государствах-участниках Содружества Независимых Государств. Несмотря на довольно-таки низкую динамику по преодолению данной проблемы, тем не менее уже существует комплекс таких модельных нормативных актов. Так, по данным СПС «КонсультантПлюс» на 29 сентября 2016 г., в рамках СНГ принято и действует 252 модельных закона, 2 модельных законодательных акта и 37 модельных кодексов. Как неоднократно отмечают специалисты-практики, это будет более сложный процесс по соотнесению их с модельным законодательством субъектов Федерации, отмеченные ими сложности, тем не менее, не выявляют объективных причин по их устранению. Внедрение модельного уголов- ного кодекса для государств-участников СНГ смогло бы снизить ряд отмеченных проблем и сформировать при этом систему международных органов власти по борьбе с межгосударственной преступностью [1, с. 67]. Но 20 апреля 2006 г. Россия, не дожидаясь завершения данных процессов, произвела ратификацию международной конвенции «О предупреждении терроризма» [6].

\section{Роль ЭВМ-комплексов в реализации принципов системности норм права}

Исполняя государственный заказ в 1997 г. по поручению Российского фонда правовых реформ, АО «КонсультантПлюс» изучает методологию создания более ранних классификаторов. Разработчики проанализировали более 50 видов систем классификации и опросили более 150 специалистов, непосредственно работавших с системами по классификации норм актов.

По результатам анализа были сделаны выводы о необходимости разработки новых систем по классификации [5]. Также были разработаны обобщенные подходы к реализации концептуальных систем по классификации правовых актов РФ.

Дальнейшие работы по формированию элементов системы классификации норм права предусматривали несколько вариантов реализации классификаторов. Каждый последующий являлся формой развития предыдущего. Все эти материалы были в 1998-1999 гг. опубликованы в сети Интернет на специальных правовых серверах (к примеру, на сайте www.consultant.ru). Каждый этап работ предполагал утверждение его Российским фондом правовых реформ.

Такие методики в работе использовались с целью учета как можно большего количества видов учета общественного мнения, замечаний и предложений в целях формирования классификаторов, которые были бы «продуктом общественного согласования». В случае, если данный подход будет приобретать все большее значение, он приведет к его использованию «де-факто» как стандарта в области классификации норм права.

По результатам широкого общественного обсуждения было получено порядка 
3000 разнообразных замечаний как общего, так и конкретного характера, а также предложений от ведущих ученых, руководителей юридических служб в органах государственной власти, а также действующих экспертов Российского фонда правовых реформ.

Деятельность экспертов заслуженно получила положительные отзывы, а сотрудники АО «КонсультантПлюс» смогли сформировать команду специалистов, имеющих значительный практический опыт по классификации норм права. Итогом деятельности по систематизации законодательства стало создание постоянно действующего научного совета АО «КонсультантПлюс» под руководством первого заместителя председателя совета исследовательского центра частного права при Президенте Российской Федерации, профессора, доктора юридических наук А.Л. Маковского.

Формированию основных классификаторов на рубеже 2001-2002 гг. АО «КонсультантПлюс» послужило основание по практическому тестированию разработанных систем классификации норм права России. Были подготовлены компьютерные демонстрационные модели, реализующие разработанные системы по классификации. В них были прорубрицированы массивы основных правовых актов РФ. Эти модели были установлены специалистами различных министерств, ведомств для практической апробации. Положительные отзывы специалистов подтверждают возможность широкого внедрения данных систем классификации правовых актов РФ в деятельность соответствующих структур.

Проведенное авторами исследование подтверждает постулат о приоритетности предметного классификатора в сочетании, естественно, с остальными видами поиска для юристов, работающих в области систематизации права. Для неимеющих юридического образования, но активно работающих с систематизацией правовой информации наибольшее значение имеют автоматические полнотекстовые формы поиска в сочетании с реквизитационным [3].

Современная наука вводит и признает следующие виды критериев систематизации норм права: 1) по органу, принявшему нормативный акт; 2) по форме правового акта (формальный принцип); 3 ) по типу акта (типовой принцип); 4) предметный (тематический); 5) алфавитный; 6) хронологический (даты вступления в силу, регистрации, поступления документа в систему); 7) смешанный принцип.

При этом разработчики справочных компьютерных правовых систем в целях удовлетворения пожеланий большого количества пользователей также реализуют все данные виды систематического поиска в разрабатываемых ими системах. Последние версии разработок также были дополнены и рядом новых. В частности: 8) интеллектуальный (косвенный поиск информации); 9) по регистрационному коду документа; 10) в зависимости от статуса акта права (не вступивший в силу, действующий акт, отмененный акт); 11) определение обратных ссылок правового акта.

Современные проблемы систематизации современного российского законодательства могут быть преодолены не только деятельностью законодательных органов власти, но и практикой использования разработок функционирующих в Российской Федерации справочных правовых компьютерных систем. Полученные достижения позволили выделить следующие индикативные критерии поиска норм права, которые при этом также могут стать и формами по их последующей систематизации: 1) интеллектуальный (косвенный поиск информации); 2) по регистрационному коду документа; 3) в зависимости от статуса правового акта (не вступивший в силу, действующий акт, отмененный акт); 4) определение обратных ссылок правового акта.

\section{Выводы}

Авторы, выделяя ряд проблем и форм систематизации права на уровне субъекта Федерации с использованием материалов по Волгоградской области, предлагают следующие рекомендации, направленные на активизацию деятельности и создание информационных банков данных по нормативным правовым актам как страны, так и регионов [4]:

1. Формирование законодательного массива требует их анализа, предоставления населению четкой и полной информации о них, а также создания государственно поддержива- 
емых информационных банков данных, содержащих нормативные правовые акты страны и региона.

2. Определение значимости совершенствования практики использования кодификации в субъектах РФ, которая имеет различные формы сотрудничества в данной области, а также обмен опытом использования кодификационных форм, конкретными проектами кодификационных актов и т. д.

3. В связи с значительным отставанием нормотворческой деятельности от правоприменительной практики, не дождавшись «внятных и эффективных» решений в области систематизации со стороны органов власти, продолжается интенсивное использование частных разработок в виде справочных правовых компьютерных систем.

\section{СПИСОК ЛИТЕРАТУРЫ}

1. Волженкин, Б. В. Модельный Уголовный кодекс для государств-участников Содружества Независимых Государств / Б. В. Волженкин // Государство и право. - 1996. - № 5. - С. 67-75.

2. Егоров, Г. Г. Роль справочных правовых компьютерных систем в систематизации российского законодательства: вопросы теории и практики : дис. ... канд. юрид. наук / Егоров Геннадий Геннадьевич. - Волгоград, 2006. - 232 с.

3. Егоров, Г. Г. Систематизация российского законодательства как способ устранения депривационных условий / Г. Г. Егоров // Личностная депривация: юридический, психологический, междисциплинарный аспекты : коллектив. моногр. Т. 1 / отв. ред. В. М. Мелихов, О. Н. Макаренко, Г. Г. Егоров. - Волжский : Царицынская полиграфическая компания, 2014. - Гл. 4. - С. 54-73.

4. Егоров, Г. Г. Эффективность справочных правовых компьютерных систем как фактор улучшения качества систематизации российского законодательства / Г. Г. Егоров // Вестник Саратовской государственной юридической академии. - 2014. № 4 (99). - С. 75-80.

5. Концепция системы классификации правовых актов РФ от 29 сент. 1999 г. : (подгот. АО «КонсультантПлюс» в рамках исполнения государственного заказа по поручению Российского фонда правовых реформ). - Доступ из справ.-правовой системы «КонсультантПлюс».

6. Международная конвенция «О предупреждении терроризма» // Собрание законодательства РФ. - 2006. - 24 апр. - № 17 (ч. І). - Ст. 1785.
7. Минеев, О. А. Проблемы правового регулирования электронной торговли в РФ / О. А. Минеев // Актуальные проблемы юридической теории и практики : коллектив. моногр. - Волгоград : Волгоградское научное издательство, 2016. - Гл. 2. -С. 18-29.

8. Минеев, О. А. Проблемы реализации принципа надлежащего исполнения обязательств в современном гражданском обороте / О. А. Минеев // Вестник Волгоградского государственного университета. - 2013. - № 1 (18). - С. 35-39.

9. Пиголкин, А. С. Проблемы систематизации законодательства Российской Федерации / А. С. Пиголкин // Закон: создание и толкование / под ред. А. С. Пиголкина. - М. : Сиарк, 1998. -С. 56-64.

10. Сенякин, И. Н. К вопросу о принципах российского законодательства (общетеоретический аспект) / И. Н. Сенякин // Защита субъективных прав: история и современные проблемы : сб. ст. по итогам Междунар. науч.-практ. конф., г. Волжский, 26 апр. 2006 г. - Волгоград : Волгоградское научное издательство, 2006. - С. 96-106.

11. Шестакова, Е. В. Международная практика применения модельного законодательства / Е. В. Шестакова // Законодательство и экономика. - 2006. - № 2. - С. 13-23.

\section{REFERENCES}

1. Volzhenkin B.V. Modelnyy Ugolovnyy kodeks dlya gosudarstv-uchastnikov Sodruzhestva Nezavisimykh gosudarstv [Model Penal Code for the State of the Commonwealth of Independent States]. Gosudarstvo i pravo, 1996, no. 5, pp. 67-75.

2. Egorov G.G. Rol spravochnykh pravovykh kompyuternykh sistem $v$ sistematizatsii rossiyskogo zakonodatelstva: voprosy teorii i praktiki: dis. ... kand. yurid. nauk [Role of Help Legal Computer Systems in the Systematization of Russian Legislation: Theory and Practice Questions. Cand. jurid. sci. diss.]. Volgograd, 2006. 232 p.

3. Egorov G.G. Sistematizatsiya rossiyskogo zakonodatelstva kak sposob ustraneniya deprivatsionnykh usloviy [Systematization of Russian Legislation as a Way to Eliminate the Conditions of Deprivation]. Melikhov V.M., Makarenko O.N., Egorov G.G., eds. Lichnostnaya deprivatsiya: yuridicheskiy, psikhologicheskiy, mezhdistsiplinarnyy aspekty: kollektivnaya monografiya. T. 1 [The Personal Deprivation: Legal, Psychological, Interdisciplinary Aspects: Collective Monograph. Vol. 1]. Volzhskiy, Tsaritsynskaya Printing Company, 2014, chapter 4, pp. $54-73$.

4. Egorov G.G. Effektivnost spravochnykh pravovykh kompyuternykh sistem kak faktor uluchsheniya kachestva sistematizatsii rossiyskogo zakonodatelstva [The Effectiveness of Legal Reference Computer Systems as a Factor in Improving the Quality 
of Systematization of Russian Legislation]. Vestnik Saratovskoy gosudarstvennoy yuridicheskoy akademii, 2014, no. 4 (99), pp. 75-80.

5. Kontseptsiya sistemy klassifikatsii pravovykh aktov RF ot 29 sentyabrya 1999 g.: (podgotovlen AO “KonsultantPlyus" v ramkakh ispolneniya gosudarstvennogo zakaza po porucheniyu Rossiyskogo fonda pravovykh reform) [The Concept of the System of Classification of Legal Acts of the Russian Federation" of September 29, 1999 (Prepared by "KonsultantPlus" in the Execution of the State Order on Behalf of the Russian Foundation for Legal Reforms)]. Access from reference legal system "KonsultantPlus".

6. Mezhdunarodnaya konventsiya "O preduprezhdenii terrorizma" [International Convention "On Prevention of Terrorism"]. Sobranie zakonodatelstva RF,2006, April24, no. 17 (partI), art. 1785.

7. Mineev O.A. Problemy pravovogo regulirovaniya elektronnoy torgovli v RF [The Gaps in the Legal Regulation of Electronic Transactions in Public Circulation]. Aktualnye problemy yuridicheskoy teorii i praktiki: kollektivnaya monografiya [Current Problems of Legal Theory and Practice: Collective Monograph]. Volgograd, Volgogradskoe nauchnoe izdvo, 2016, chapter 2, pp. 18-29.

8. Mineev O.A. Problemy realizatsii printsipa nadlezhashchego ispolneniya obyazatelstv $\mathrm{v}$ sovremennom grazhdanskom oborote [Problems of Realization of the Principle of Proper Fulfillment of Obligations in the Modern Civil Turnover]. Vestnik Volgogradskogo gosudarstvennogo universiteta. Yurisprudentsiya [Science Journal of Volgograd State University. Jurisprudence], 2013, no. 1 (18), pp. 35-39.

9. Pigolkin A.S. Problemy sistematizatsii zakonodatelstva Rossiyskoy Federatsii [Problems of Systematization of Legislation of the Russian Federation]. Pigolkin A.S., ed. Zakon: sozdanie $i$ tolkovanie [Act: Creation and Interpretation]. Moscow, Siark Publ., 1998, pp. 56-64.

10. Senyakin I.N. K voprosu o printsipakh rossiyskogo zakonodatelstva (obshcheteoreticheskiy aspekt) [On the Issue of the Principles of Russian Legislation (General Theoretical Aspect)]. Zashchita subyektivnykh prav: istoriya i sovremennye problemy: sbornik statey po itogam Mezhdunarodnoy nauchnoprakticheskoy konferentsii, g. Volzhskiy, 26 aprelya 2006 g. [Protection of Rights: History and Contemporary Issues: Collection of Articles on the Results of the International Scientific-Practical Conference, Volzhsky, April 26, 2006]. Volgograd, Volgogradskoe nauchnoe izd-vo, 2006, pp. 96-106.

11. Shestakova E.V. Mezhdunarodnaya praktika primeneniya modelnogo zakonodatelstva [International Practice of Model Legislation]. Zakonodatelstvo i ekonomika, 2006, no. 2, pp. 13-23.

\section{Information About the Authors}

Oleg A. Mineev, Candidate of Juridical Sciences, Associate Professor, Head of Department of Civil Law, Volzhsky Humanitarian Institute, 40 let Pobedy St., 11, 404133 Volzhsky, Russian Federation, oleg_min@mail.ru.

Gennadiy G. Egorov, Candidate of Juridical Sciences, Associate Professor, Head of Department of Constitutional and Administrative Law, Volzhsky Humanitarian Institute, 40 let Pobedy St., 11, 404133 Volzhskiy, Russian Federation, egorov@vgi.volsu.ru, ob.otdel@vgi.volsu.ru.

\section{Информация об авторах}

Олег Александрович Минеев, кандидат юридических наук, доцент, заведующий кафедрой гражданского права, Волжский гуманитарный институт, ул. 40 лет Победы, 11, 404133 г. Волжский, Российская Федерация, oleg_min@mail.ru.

Геннадий Геннадьевич Егоров, кандидат юридических наук, доцент, заведующий кафедрой конституционного и административного права, Волжский гуманитарный институт, ул. 40 лет Победы, 11, 404133 г. Волжский, Российская Федерация, egorov@vgi.volsu.ru, ob.otdel@vgi.volsu.ru. 